\title{
3 Research Square

\section{Exploration of Associations Between Deliberate Self-Poisoning and Psychiatric Disorders in Rural Sri Lanka: A Case Control Study}

P. H. G. J. Pushpakumara ( $\sim$ janaka@med.rjt.ac.lk)

Rajarata University of Sri Lanka https://orcid.org/0000-0002-8680-4397

\section{A. M. P. Adikari}

Teaching Hospital Kurunegala

\section{T. N. Rajapakse}

University of Peradeniya Faculty of Medicine

\section{S. U. B. Thennakoon}

University of Peradeniya Faculty of Medicine

\section{Ranil Abeysinghe}

University of Peradeniya Faculty of Medicine

\section{A. H. Dawson}

The University of Sydney Central Clinical School

\section{Research article}

Keywords: Self-harm, Psychopathology, Sri Lanka, Suicide, Psychiatric disorder, Depression, Alcohol, Personality disorder

Posted Date: May 14th, 2020

DOl: https://doi.org/10.21203/rs.3.rs-23796/v1

License: (9) This work is licensed under a Creative Commons Attribution 4.0 International License. Read Full License

Version of Record: A version of this preprint was published at PLOS ONE on August 6th, 2021. See the published version at https://doi.org/10.1371/journal.pone.0255805. 


\section{Abstract}

Background Psychiatric disorders are important predictors of self-harm behaviour. The present study was carried out to determine associations between DSM-IV TR Axis- I \& II disorders and deliberate self poisoning (DSP) in a Sri Lankan rural agricultural district.

Methods Patients who had attempted DSP, who resided within the district were selected randomly for the study. Both the cases and age, sex and residential area matched controls were assessed for DSM-IV TR Axis- I \& II disorders based on the Structured Clinical Interview for DSM-IV-TR Axis I and II Disorders (SCID I \& II) conducted by a specialist psychiatrist.

Results Cases consisted of 207 (47.3\%) males and 231 (52.7\%) females. TR axis-I and/or TR axis-II psychiatric diagnoses was found in $89(25.6 \%)$ of cases and $14(3.2 \%)$ controls. Cases with a TR axis-I diagnosis were older (32 and 19 years), $p<0.0001$. Having a depressive episode was associated with a 13 time higher risk for DSP. Being a male aged $>=30$ years and having an alcohol use disorder carried a 21 time excess risk for DSP. A fivefold excess risk for DSP was found among 10-19 years old females with borderline personality traits.

Conclusions Depressive disorder and alcohol related disorders were significantly associated with older participants who had attempted DSP. The prevalence of psychiatric disorders among DSP in rural Sri Lanka is significantly lower than reported rates in western countries. Health and research priorities to reduce self-harm in Sri Lanka will also need to address non-psychiatric issues

\section{Background}

Deliberate self-harm (DSH) is a global health issue which is responsible for about 800000 deaths each year.[1] Studies show that the rates of non fatal suicidal behaviours is 10 to 40 times greater than suicide. $[2,3]$ Rural areas of Sri Lanka (SL) have had a persistently high incidence of deliberate self-poisoning (DSP) since the early 1980s.[4-6]

A major psychiatric diagnosis is one predictor of both DSH and subsequent suicide.[7] Moreover, personality traits $[8,9]$ and personality disorders have been identified as risk factors for DSH.[10] The high rates of self-harm in SL are multifactorial, with both cultural and environmental factors playing a role. The contribution of psychiatric disorders to DSH is important in health care planning but has not been described in detail. Most previous Sri Lankan studies of psychiatric disorders in DSH have been based upon self-report, use of screening tools or review of medical records. A systematic review of studies of self-harm in Sri Lanka [11] did not identify any studies that investigated possible associations between non-fatal self-poisoning and psychiatric conditions such as anxiety disorders, impulse control disorders, or bipolar disorder.

The present study was designed to determine associations between DSM-IV TR Axis- I \& II disorders, assessed using the Structured Clinical Interview for DSM-IV-TR Axis I and II Disorders (SCID I \& II) by a 
specialist psychiatrist, and deliberate self poisoning (DSP) in the Kurunegala District (KD), Sri Lanka.

\section{Methods}

\section{Study design and study setting}

An age, sex and residential divisional secretariat division matched case control study was conducted among randomly selected patients who were admitted to Teaching Hospital Kurunegala (THK) over a period of eighteen months, from 1st July 2011 to 31 st December 2013, as a sub study of the study titled "A clustered randomise control trial of educational interventions on treatment of patients with acute poisoning in rural Asian hospitals" (Sri Lanka Clinical Trial Registry No. SLCTR/2010/008). THK is the main referral center for the 1.6 million population of the district,[12] and receives more than $53 \%$ of the total deliberate self-poisoning cases of the district.[6]

\section{Procedure}

\section{Sample and sampling:}

Sample size was calculated for hypothesis testing for an odds ratio, with level of $5 \%$ significance and two-sided test with power of $90 \%$. The sample size was calculated to detect a condition which has a $6 \%$ prevalence among the non-DSP population and minimum odds of two or a condition which has a $1 \%$ prevalence among non-DSP population and minimum odds of 3.75.[13] Four hundred and thirty-eight patients who had attempted DSP, who reside within the Kurunegala District, were selected as cases randomly from blocks of seven consecutively admitted consenting DSP patients, aged 10 years and above, using a computer program. The same number of age, sex and residential divisional secretariat division matched individuals, who have no history of self-harm, were randomly selected as controls from patients presenting to the Out Patient Department (OPD), THK.

\section{Study Instruments And Data Collection:}

A consultant psychiatrist interviewed all participants (cases and controls) using the SCID I \& II to diagnose any major psychiatric disorders and/or personality disorders (DSM-IV-TR Axis I and II disorders). Collateral history was obtained from family members. The diagnoses were recorded according to DSM-IV. [14] Interviews were conducted when the participants were medically stable, usually the day before the day of discharge in cases, and after the OPD consultation in controls. Details related to the previous consultations of health professional for the symptoms related to the diagnosis were collected through an interview with the patient and relation, and confirmed by examination of previous medical records.

\section{Data analysis}


Data were entered to a Microsoft Excel spreadsheet and analyzed using IBM SPSS Statistics for Windows, Version 23.0. Medians, quartiles and percentages with a confidence interval at $95 \%$ significant level were calculated to describe variables. Odds ratios and confidence interval at $95 \%$ significant level were calculated for categorical data.

\section{Role Of The Funding Source}

The funders had no role in study design, data collection and analysis, decision to publish, or preparation of the manuscript.

\section{Results}

A total of 1954 and 2049 persons were admitted for DSP in 2011 and 2012 respectively. The sample consisted of 207 (47.3\%) males and 231 (52.7\%) females, ranging from 12 to 70 years of age (median 20, IQR 17-27). More than one third (37\%) of males and more than half $(53.7 \%)$ of females were aged below 20 years. Males were older than females, and the median age of males was 22 years (IQR 18-32) and of females was 19 years (IQR 17-24), respectively, $p<0.0001$ (Mann-Whitney U test).

A TR axis-I and/or TR axis-II psychiatric diagnosis was present in 89 (25.6\%, 95\% Cl 21.5-29.7\%) of cases and $14(3.2 \%, 95 \% \mathrm{Cl} 1.5-4.8 \%)$ controls. More than one psychiatric condition was found in 14 $(3.2 \%, \mathrm{Cl} 1.5-4.8 \%)$ of cases and in none of the controls. Having a psychiatric disorder was associated with a 7.7 times higher risk for DSP $(\mathrm{OR} 7.7,95 \% \mathrm{Cl} 4.3-13.8, \mathrm{p}<0.0001$ Chi-square test). Cases who had at least one TR axis-I diagnosis (median age 32 years, IQR 20.75-43) were older than those who had no psychiatric disorder (median age 19 years, IQR 17-24), $\mathrm{p}<0.0001$ (Mann-Whitney $\mathrm{U}$ test). The prevalence of a depressive episode among patients who presented with DSP was $8.4 \%$ (95\% Cl 3.5-13.6\%).

Suffering from a depressive episode was shown to have a 13 times excess risk for DSP (OR 13.4, 95\% Cl 4.1-43.7, $\mathrm{p}<0.0001$ Chi-square test). A large majority, 76.4\% (95\% Cl 68.9-83.9) had never sought medical care for the symptoms related to their psychiatric diagnosis (Table 1). 
Table 1

Presence of TR axis-I and II psychiatric disorders among cases

\begin{tabular}{|c|c|c|}
\hline Diagnosis & $\mathrm{n}(\%, 95 \% \mathrm{Cl})$ & $\begin{array}{l}\text { Newly diagnosed: } \mathrm{n}(\%, \\
95 \% \mathrm{Cl})\end{array}$ \\
\hline Alcohol Dependence & $9(2.0,0.7-3.3)$ & $7(77.8,63.9-91.6)$ \\
\hline Alcohol abuse & $\begin{array}{l}13(3.0,1.4- \\
4.6)\end{array}$ & $11(84.6,78.2-90.9)$ \\
\hline Poly-substance dependence & $\begin{array}{l}1(0.2,-0.2- \\
0.6)\end{array}$ & $1(100)$ \\
\hline Mild Depressive disorder, single episode & $5(1.1,0.1-2.0)$ & $5(100)$ \\
\hline Moderate Depressive disorder, single episode & $\begin{array}{l}12(2.7,1.2- \\
4.2)\end{array}$ & $9(75,67.3-82.6)$ \\
\hline $\begin{array}{l}\text { Severe Depressive disorder without psychotic features, } \\
\text { single episode }\end{array}$ & $\begin{array}{l}13(3.0,1.4- \\
4.6)\end{array}$ & $11(84.6,78.2-90.9)$ \\
\hline Recurrent Moderate Depressive disorder & $\begin{array}{l}3(0.7,-0.1- \\
1.5)\end{array}$ & $0(0)$ \\
\hline $\begin{array}{l}\text { Recurrent Severe Depressive disorder without } \\
\text { psychotic features }\end{array}$ & $\begin{array}{l}2(0.5,-0.2- \\
1.2)\end{array}$ & $1(50,14.6-85.4)$ \\
\hline $\begin{array}{l}\text { Recurrent Severe Depressive disorder with psychotic } \\
\text { features }\end{array}$ & $\begin{array}{l}1(0.2,-0.2- \\
0.6)\end{array}$ & $1(100)$ \\
\hline $\begin{array}{l}\text { Bipolar Affective Disorder-most recent episode } \\
\text { moderate depression }\end{array}$ & $\begin{array}{l}1(0.2,-0.2- \\
0.6)\end{array}$ & $1(100)$ \\
\hline Schizophrenia & $2(0.4,2.1-5.8)$ & $0(0)$ \\
\hline Acute Stress Disorder & $\begin{array}{l}1(0.2,-0.2- \\
0.6)\end{array}$ & $1(100)$ \\
\hline Specific phobia & $\begin{array}{l}2(0.5,-0.2- \\
1.2)\end{array}$ & $1(50,14.6-85.4)$ \\
\hline Moderate Mental Retardation & $\begin{array}{l}1(0.2,-0.2- \\
0.6)\end{array}$ & $0(0)$ \\
\hline Borderline Personality Disorder or traits & $\begin{array}{l}32(7.3,4.5- \\
9.7)\end{array}$ & $25(78.1,70.8-85.4)$ \\
\hline Antisocial Personality Disorder or traits & $\begin{array}{l}3(0.7,-0.1- \\
1.5)\end{array}$ & $2(66.7,39.5-93.9)$ \\
\hline Narcissistic Personality Disorder or traits & $\begin{array}{l}1(0.2,-0.2- \\
0.6)\end{array}$ & $1(100)$ \\
\hline Depressive Personality Disorder or traits & $\begin{array}{l}2(0.5,-0.2- \\
1.2)\end{array}$ & $0(0)$ \\
\hline Obsessive Compulsive Personality Disorder or traits & $0(0)$ & 0 \\
\hline
\end{tabular}




\section{Alcohol Use Disorders}

Several studies have shown strong associations between alcohol and suicidal behavior in Sri Lanka. [38, 39]. The marked male predominance of alcohol use in this study, which has also been reported by previous Sri Lankan studies and rest of the Asia, [40] reflects the socio-cultural norms of alcohol use in this country. In this study the presence of an alcohol use disorder was associated with a 21 times increased risk of DSP. This was the most significant risk factor associated with DSP for males, which highlights the importance of alcohol use disorders in DSP behaviour [15]. This is supported by findings from other studies in Sri Lanka.[16, 41, 42]. Interpersonal conflict, and domestic, physical, sexual or psychological abuse associated with alcohol misuse are likely to contribute to DSH behavior [41], both in the person who misuses alcohol as well as their close family members. Alcohol use and alcohol related domestic violence among males is associated with increased risk of psychiatric disorders among their partners and wives [43]. Alcohol use disorders are also associated with increased risk of depression and suicidal behaviour among those who consume alcohol.[44] A recent study has proposed a model to explain suicide proneness in alcohol use through alcohol-related problems; negative life events and depressive symptoms, and it is likely that multiple complex factors contribute to the increased risk of selfharm seen in those with alcohol use disorders in this study. [45]

Though the reported prevalence of other substance dependence is very low in the present study, a higher prevalence of cannabis has been reported in previous studies [46][477] specially among adolescents. [48] Analysis of data published by Sri Lanka Police reported that, 2664 (6.3\% of all suicide) suicides had concurrent psychoactive substance use, in the 2005 to 2015 ten year period.[49] 
Table 2

Presence of alcohol use disorder among cases and controls by age group

\begin{tabular}{|c|c|c|c|c|c|}
\hline \multirow{3}{*}{$\begin{array}{l}\text { Age Group } \\
\text { (years) }\end{array}$} & \multicolumn{3}{|l|}{ Male } & \multicolumn{2}{|l|}{ Female } \\
\hline & \multicolumn{2}{|c|}{$\begin{array}{l}\text { n, \% (95\% Cl) having alcohol } \\
\text { use disorder }\end{array}$} & \multirow{2}{*}{$\begin{array}{l}\text { OR* } \\
(95 \% \mathrm{Cl}) \\
\text { p value }\end{array}$} & \multicolumn{2}{|c|}{$\begin{array}{l}\mathrm{n}, \%(95 \% \mathrm{Cl}) \text { having alcohol } \\
\text { use disorder }\end{array}$} \\
\hline & Case & Control & & Case & Control \\
\hline \multirow[t]{2}{*}{$10-19$} & $2,2.6$ & $1,1.3$ & $2.0(0.18$ - 22.84), & $1,0.8$ & \multirow{2}{*}{$\begin{array}{l}1,0.8(0.003- \\
1.6)\end{array}$} \\
\hline & $(0.8-4.4)$ & $\begin{array}{l}(0.01- \\
2.6)\end{array}$ & 1.0 & $\begin{array}{l}(0.003- \\
1.6)\end{array}$ & \\
\hline \multirow[t]{2}{*}{$20-29$} & $3,4.2$ & $1,1.4$ & \multirow{2}{*}{$\begin{array}{l}3.1(0.31-30.44) \\
0.62\end{array}$} & \multirow[t]{2}{*}{0} & $1,1.3$ \\
\hline & $(1.8-6.6)$ & $\begin{array}{l}(0.01- \\
2.8)\end{array}$ & & & $(0.01-2.7)$ \\
\hline \multirow[t]{2}{*}{$>=30$} & \multirow{2}{*}{$\begin{array}{l}16,26.7(20.9- \\
32.4)\end{array}$} & $1,1.7$ & \multirow{2}{*}{$\begin{array}{l}21.4(2.74-168.0), \\
<0.0001\end{array}$} & \multirow[t]{2}{*}{0} & \multirow[t]{2}{*}{0} \\
\hline & & $\begin{array}{l}(0.01- \\
3.3)\end{array}$ & & & \\
\hline
\end{tabular}

* unadjusted odds ratios $\quad$ ** $p$ value of Fisher's exact test

\section{Depressive Disorders}

The highest proportion of depressive episodes was found in the $>=30$ year age group, with the gender distribution being $20 \%$ among males and $28 \%$ among females. Cases who presented with a current episode of depression were older (median age 35 years, IQR 20.5-45) than the cases who had no depressive episode (median age 20 years, IQR 17-25), p < 0.0001 (Mann-Whitney U test). Females aged > $=30$ years with a current episode of depression had a higher risk for DSP (OR 26.3,95\% CI 1.5-474.5, $p=$ 0.002 , Fisher's exact test) compared to same aged males having a current episode of depression (OR 4.7, $95 \% \mathrm{Cl} 1.3-17.8, \mathrm{p}=0.02$, Fisher's exact test). Nearly one fourth, $24.3 \%$ (95\% Cl 16.7-31.9) of those who were depressed had sought medical care for a depressive disorder prior to the event. 
Table 3

Presence of depressive episode among cases and controls by age group

\begin{tabular}{|c|c|c|c|c|c|c|}
\hline \multirow{3}{*}{\multicolumn{2}{|c|}{$\begin{array}{l}\text { Age Group Male } \\
\text { (years) }\end{array}$}} & \multicolumn{5}{|c|}{ Female } \\
\hline & & \multirow{3}{*}{$\begin{array}{l}\text { OR* } \\
(95 \% \mathrm{Cl}) \\
\text { p value }\end{array}$} & \multirow{2}{*}{\multicolumn{2}{|c|}{$\begin{array}{l}\text { n, \% (95\% Cl) having } \\
\text { depressive episode }\end{array}$}} & \multirow{3}{*}{$\begin{array}{l}\text { OR* } \\
(95 \% \mathrm{Cl}) \\
\mathrm{p} \\
\text { value**}\end{array}$} & \\
\hline & & & & & & \\
\hline Case & Control & & Case & Control & & \\
\hline \multirow[t]{3}{*}{$10-19$} & \multirow{3}{*}{$\begin{array}{l}2,2.6(0.8- \\
4.4)\end{array}$} & \multirow[t]{3}{*}{0} & & \multirow{3}{*}{$\begin{array}{l}\text { 4, } 3.2(1.6- \\
4.8)\end{array}$} & \multirow[t]{3}{*}{0} & 9.3 \\
\hline & & & $\begin{array}{l}(0.2 \text { to } \\
108.8)\end{array}$ & & & $\begin{array}{l}(0.5 \text { to } \\
174.7)\end{array}$ \\
\hline & & & 0.49 & & & 0.12 \\
\hline \multirow[t]{3}{*}{$20-29$} & \multirow{3}{*}{$\begin{array}{l}5,7.0(4.0- \\
10.1)\end{array}$} & \multirow[t]{3}{*}{0} & 11.8 & \multirow{3}{*}{$\begin{array}{l}5,6.7(3.8- \\
9.5)\end{array}$} & \multirow[t]{3}{*}{0} & 11.8 \\
\hline & & & $\begin{array}{l}(0.6 \text { to } \\
218.2)\end{array}$ & & & $\begin{array}{l}(0.6 \text { to } \\
217.1)\end{array}$ \\
\hline & & & 0.058 & & & 0.058 \\
\hline \multirow[t]{3}{*}{$>=30$} & \multirow{3}{*}{$\begin{array}{l}12,20.0 \\
(14.8-25.2)\end{array}$} & \multirow{3}{*}{$\begin{array}{l}3,5.0 \\
(2.2-7.8)\end{array}$} & 4.7 & \multirow{3}{*}{$\begin{array}{l}9,28.1(20.2- \\
36.1)\end{array}$} & \multirow[t]{3}{*}{0} & 26.3 \\
\hline & & & $\begin{array}{l}\text { (1.3 to } \\
17.8)\end{array}$ & & & $\begin{array}{l}(1.5 \text { to } \\
474.5)\end{array}$ \\
\hline & & & 0.02 & & & 0.002 \\
\hline
\end{tabular}

\section{Borderline Personality Disorder (bpd) And Borderline Personality Traits (bpt)}

The prevalence of BPD or BPT among persons who attempted DSP did not significantly differ between age groups. Similarly, there was no difference in the median age of patients diagnosed to have and excluded BPD or BPT. The median age of those with BPD or BPT was 20.5 years (IQR 16.25 to 30.00), and the median age of others was 20.0 years (IQR 17.0 to 26.0), $p=0.8$ (Mann-Whitney $U$ test). A fivefold excess risk for DSP was found among 10-19 years old females with BPT (OR 5.3, 95\% Cl 1.1-24.9, $p=$ 0.03 , Fisher's exact test). However, there was no significant association of BPD with DSP. Slightly over one fifth of patients $(21.8 \%, 95 \% \mathrm{Cl} 14.5-29.2)$ had sought medical care for symptoms related to the personality disorder prior to the event. 
Table 4

Presence of BPD or BPT among cases and controls by age group

\begin{tabular}{|c|c|c|c|c|c|c|}
\hline $\begin{array}{l}\text { Age Group } \\
\text { (years) }\end{array}$ & Male & & & Female & & \\
\hline $\begin{array}{l}\mathrm{n}, \%(95 \% \mathrm{C} \\
\mathrm{BPD}\end{array}$ & laving & $\begin{array}{l}\text { OR* }(95 \% \mathrm{Cl}) \mathrm{p} \\
\text { value }\end{array}$ & $\begin{array}{l}\mathrm{n}, \%(95 \\
\mathrm{BPD}\end{array}$ & I) having & $\begin{array}{l}\text { OR* }(95 \% \mathrm{Cl}) \mathrm{p} \\
\text { value }\end{array}$ & \\
\hline Case & Control & & Case & Control & & \\
\hline $10-19^{\#}$ & $5,6.5$ & $1,1.3(0.01-$ & 5.3 & $10,8.1$ & 0 & 5.3 \\
\hline & & & $\begin{array}{l}(0.6 \text { to } \\
46.3)\end{array}$ & & & $\begin{array}{l}(1.1 \text { to } \\
24.9)\end{array}$ \\
\hline & & & 0.21 & & & 0.03 \\
\hline $20-29^{\# \#}$ & $\begin{array}{l}3,4.2 \\
(1.8-6.6)\end{array}$ & 0 & 7.3 & 5, 6.7 (3.8- & 0 & 11.8 \\
\hline & & & $\begin{array}{l}(0.4 \text { to } \\
144.2)\end{array}$ & & & $\begin{array}{l}(0.6 \text { to } \\
217.1)\end{array}$ \\
\hline & & & 0.24 & & & 0.058 \\
\hline$>=30^{\# \#}$ & $\begin{array}{l}4,6.7 \\
(3.4-9.9)\end{array}$ & 0 & 9.6 & $\begin{array}{l}5,15.6 \\
(92-220)\end{array}$ & 1, 3.1 (0.05- & 5.7 \\
\hline & & & $\begin{array}{l}(0.5 \text { to } \\
183.2)\end{array}$ & & & $\begin{array}{l}(0.6 \text { to } \\
52.3)\end{array}$ \\
\hline & & & 0.12 & & & 0.19 \\
\hline
\end{tabular}

\section{Discussion}

\section{Rates of psychiatric morbidity}

This is the first large study on DSP in Sri Lanka which used the DSM-IV based SCID interview conducted by a specialist in psychiatry. The prevalence of a psychiatric diagnosis among persons who have attempted DSP in the Kurunegala District in this study (25.6\%) is similar to the observations of a cross sectional study conducted in central part of the country, (32.1\%).[15] Other studies, conducted in different parts of the country including in areas socioeconomically similar to the KD, have reported relatively lower prevalence.[16-19] This variation may be explained by the difference in sub-cultures and under-diagnosis or over-diagnosis of psychiatric disorders due differences in methodology and diagnostic tools used to elicit psychiatric disorders.[20]

The previous reported prevalence of psychiatric diagnoses among those who attempted suicide have been lower among Asians [21] compared to those in western countries, where some studies reported at least one Axis I disorder in $98 \%$ of cases, [22-24] The possibility of underestimating psychiatric disorders due to the stigma of mental illness, methodological limitations, as well as limited treatment resources in developing countries have been proposed to explain these variations.[25] A recent systematic review has 
highlighted the scarcity of high-quality research and high level of heterogeneity of reported prevalence in low and middle income countries. [26] In this study, in order to minimize these bias, SCID based clinical interviews were conducted by specialists in psychiatry, to assess for the presence of psychiatric disorders. Despite this, the findings of this study confirm a lower prevalence of psychiatric disorders among those who have attempted DSP, compared to rates reported from the west. This suggests the involvement of other non-psychiatric factors contributing towards DSP, particularly in the younger age groups. This finding may also partially explain the lower repetition rates of self-harm, observed in Sri Lanka. $[6,27]$ In this Sri Lankan context a greater focus on non-psychiatric and medical interventions many be appropriate. In rural Sri Lanka, self poisoning seems to be the preferred method of dealing with difficult situations [28]. Inability to cope with negative feelings, emotions and urges and poor decision making skills [29] and lack of skills necessary to deal with problems [15] have been identified as important in deliberate self-harm. Training on life skills including coping skills as a preventive strategy for suicide and attempted suicide maybe an area of future research worth exploring. [30-33]

\section{Psychiatric Morbidity And Risk Of Dsh}

\section{Depression}

Of the psychiatric disorders, mood disorders have been commonly [34] and consistently [35] associated with suicidal behavior. The present study, as well as a few other studies conducted previously in Sri Lanka have reported depressive disorder as the most commonly seen psychiatric disorder among those who attempt DSH. However, compared to the present prevalence of $8.4 \%$, most of the previous studies have reported a higher prevalence in depression among $\mathrm{DSH}$, ranging from $13.4-53.7 \%[15,17,36,37]$. In contrast, one study conducted in a socioeconomically similar area to this study found no significant association between DSP and depressive disorder. [16] Differences of diagnostic procedures and contextual variation may explain the observed variation.

\section{Bpd And Bpt}

Personality disorders is another significant risk factor associated with suicidal behavior.[10] At least three-quarters of patients with BPD engage in suicidal behavior.[50] A study conducted in central part of the SL also cited that personality disorders, especially impulsive personality traits, were common among DSH patients.[15] In this study in the KD, 8.7\% of who have attempted DSP were diagnosed as a having BPD or BPD traits. BPD or BPT alone associated with $7.3 \%$ of DSH events. However, the absence of a significant association between DSP and BPD maybe partially explained by the apparent relatively lower prevalence of BPD in Asians.[51]

\section{Variation Of Psychiatric Morbidity With Age}


It has been suggested that there may be significant differences between younger and older people who have suicide behaviour.[52] Sri Lankan and international researchers have described two broad categories of persons who attempt DSH - a larger proportion of younger people, usually without psychiatric disorders, in response to family or social conflicts; and less commonly older persons, who often have an often undiagnosed major psychiatric disorder, especially depression, and who may have an ongoing high risk of suicide.[15] A similar pattern of DSP was observed in the present study. Substance misuse and depressive disorders were the significant correlates of the self-harm behaviour in adults older than 30 years of age, in this study. This is a key finding -although a majority of those who attempt DSP are young (aged below 30 years), older persons who attempt DSP were significantly more likely to have a psychiatric disorder and probable high suicide risk. Ideally all persons who are admitted for management for DSH should be screened for risk factors such as depression and alcohol use disorders - but this is particularly important in older persons (over 30 years). Establishing a method of screening at least for all older persons after DSH, and further assessment as needed, should be part of routine practice. Healthcare practitioners should also be educated about the 'red flags' to identify high risk persons presenting with DSP - for example older age, previous attempts, and psychiatric morbidity. DSP among young people in this study was less likely to be associated with psychiatric morbidity. DSH among adolescents and young adults has been associated with acute emotional distress, interpersonal conflicts with close 'others' (such as parents and partners) and has even been described as a learnt maladaptive coping mechanism in challenging situations. [28,53-55] Therefore, in-depth exploration of association with life skills, which is a less explored entity in suicidology,[56] is important. Innovative methods to help young people develop problem solving and interpersonal skills should be explored and developed. Community programs to help parents understand and respond to teenage children more appropriately is another challenging but important area to be explored.

\section{Conclusions}

Depressive disorder and alcohol related disorders were significant predictors of suicidal behavior by selfpoisoning. A majority of those with psychiatric disorders were only diagnosed after the event of DSP. TR Axis-I psychiatric disorders are significantly associated with older age. The marked association between alcohol use disorders and DSP among males in this study highlights the urgent need for culturally suited effective strategies to minimize alcohol use disorders in the community, including brief interventions and identification of high risk individuals with alcohol use disorders for interventions. However, the prevalence of psychiatric disorders among DSP in rural Sri Lanka is markedly low compared to rates reported from western countries. Further research is warranted to investigate whether DSH is the same phenomenon across the life cycle or whether it has a different meaning and risk factors in adolescence and young adults compared to older people.

\section{List Of Abbreviations}

Deliberate self-harm (DSH) 
Deliberate self poisoning (DSP)

Kurunegala District (KD)

Randomise Control Trial (RCT)

Teaching Hospital Kurunegala (THK)

\section{Declarations}

\section{Ethics approval and consent to participate}

Ethics approval for "A clustered RCT of educational interventions on treatment of patients with acute poisoning in rural Asian hospitals" was obtained from Ethical Review Committee, e Faculty of Medicine, University of Peradeniya (EC/2007/98, https://med.pdn.ac.lk/admin/committees_Ethical.html). Ethical approval for the sub study was obtained from the Ethics Review Committee, Faculty of Medicine and Allied Sciences, Rajarata University of Sri Lanka (8/3/2011, http://www.rjt.ac.lk/med/facultystructure/committees/erc). Informed written consent was obtained from the participants for all the interviews and to obtain the collateral history form a third party. Ascent form the participant and consent from a parent or guardian were taken for minors, aged below 16 years.

\section{Consent for publication}

Not Applicable

\section{Availability of data and materials}

Data are available from study authors on request.

\section{Competing interests}

We declare no competing interests.

\section{Funding}

The study was supported by two Australian National Health and Medical Research Council grants: NHMRC 630650 and NHMRC Fellowship 1059542 (https://www.nhmrc.gov.au/). The funder had no role in the design of the study and collection, analysis, and interpretation of data and in writing the manuscript.

\section{Authors' contributions}

Conceptualization: P.H.G.J. Pushpakumara, Ranil Abeysinghe, A.H. Dawson.

Data curation: P.H.G.J. Pushpakumara, A.M.P. Adikari 
Formal analysis: P.H.G.J. Pushpakumara, S.U.B. Thennakoon

Supervision: Ranil Abeysinghe, A.H. Dawson, S.U.B. Thennakoon

Writing of the original draft: P.H.G.J. Pushpakumara.

Contribution \& editing of the manuscript: T.N. Rajapakse, A.H. Dawson, P.H.G.J. Pushpakumara.

Except A.M.P. Adikari, who has passed away, all the other authors have read and approved the manuscript.

\section{Acknowledgements}

We would like to thank the South Asian Clinical Toxicology Research Collaboration staff, particularly Sanjaya Rathnayake, Dilani Pinnaduwa, Thilini Siriwardhana and Nilupa Herath, for organisational support; and Prarthana Weerasekara for data management support. We also thank the director, consultant physicians, and medical and nursing staff of the Teaching Hospital Kurunegala for their support of the study. We extend or sincere gratitude to Australian National Health and Medical Research Council for financial support.

\section{References}

1. Suicide. http://www.who.int/news-room/fact-sheets/detail/suicide.

2. De Leo D, Burgis S, Bertolote JM, Kerkhof AJFM, Bille-Brahe U. Definitions of Suicidal Behavior: Lessons Learned from the WHO/EURO Multicentre Study. Crisis: The Journal of Crisis Intervention Suicide Prevention. 2006;27(1):4-15.

3. Dietrich S, Wittenburg L, Arensman E, Varnik A, Hegerl U: Suicide and Self-harm. In: Primary Care Mental Health. edn. Edited by Gask L, Lester H, Kendrick T, Peveler R. London, UK: The Royal College of Psychiatrists; 2009: 138.

4. Knipe DW, Padmanathan P, Muthuwatta L, Metcalfe C, Gunnell D. Regional variation in suicide rates in Sri Lanka between 1955 and 2011: a spatial and temporal analysis. BMC Public Health. 2017;17(1):193.

5. Senarathna L, Jayamanna SF, Kelly PJ, Buckley NA, Dibley MJ, Dawson AH. Changing epidemiologic patterns of deliberate self poisoning in a rural district of Sri Lanka. BMC Public Health. 2012;12:593.

6. Pushpakumara PHGJ, Thennakoon S, Rajapakse T, Abeysinghe R, Dawson A. A prospective study of repetition of self-harm following deliberate self-poisoning in rural Sri Lanka. PLoS ONE. 2019;14(2):e0199486.

7. Nock MK, Borges G, Bromet EJ, Alonso J, Angermeyer M, Beautrais A, Bruffaerts R, Chiu WT, de Girolamo G, Gluzman S, et al. Cross-national prevalence and risk factors for suicidal ideation, plans and attempts. Br J Psychiatry. 2008;192:98-105. 
8. Baud P. Personality traits as intermediary phenotypes in suicidal behavior: genetic issues. The American Journal of Medical Genetics C. 2005;133(1):34-42.

9. Kessler RC, Borges G, Walters EE. Prevalence of and risk factors for lifetime suicide attempts in the National Comorbidity Survey. Arch Gen Psychiatry. 1999;56(7):617-26.

10. Welch SS. A Review of the Literature on the Epidemiology of Parasuicide in the General Population. Psychiatric Services. 2001;52(3):368-75.

11. Rajapakse T, Griffiths KM, Christensen H. Characteristics of non-fatal self-poisoning in Sri Lanka: a systematic review. BMC Public Health. 2013;13:133.

12. Statistical Handbook. Kurunegala District - Population by Age groups and Gender within District 2014 (Table: 2 .8) http://www.statistics.gov.lk/statistical\%20Hbook/2015/Kurunegala/Table\%202.8.pdf.

13. Lwanga SK, Lemeshow S: Sample size determination in health studies: a practical manual: World Health Organization; 1991.

14. First MB, Spitzer RL, Gibbon M, Williams JBW: Structured Clinical Interview for DSM-IV-TR Axis I Disorders, Research Version, Non-Patient Edition. (SCID-I/NP). In. New York: Biometrics Research, New York State Psychiatric Institute; 2010.

15. de Silva HJ, Kasturiarachchi N, Seneviratne SL, Senaratne DC, Molagoda A, Ellawala NS. Suicide in Sri Lanka: points to ponder. Ceylon Med J. 2000;45:17-24.

16. van der Hoek W, Konradsen F. Risk factors for acute pesticide poisoning in Sri Lanka. Tropical Medicine International Health. 2005;10(6):589-96.

17. Seneviratne SL, Warnasooriya WM, Gunatilake SB, Fonseka MM, Gunawardena MK, de Silva HJ. Serum cholesterol concentrations in parasuicide. Ceylon Med J. 1999;44(1):11-3.

18. Chandrasena R. A transcultural evaluation of "self poisoning" in Sri Lanka. The International Journal of Social Psychiatry. 1981;27(2):119-23.

19. Senanayake N, Karalliedde L. Acute poisoning in Sri Lanka: an overview. Ceylon Med J. 1986;31(2):61-71.

20. Chen YY, Wu KC, Yousuf S, Yip PS. Suicide in Asia: opportunities and challenges. Epidemiol Rev. 2012;34(1):129-44.

21. Bhui K, McKenzie K, Rasul F. Rates, risk factors \& methods of self harm among minority ethnic groups in the UK: a systematic review. BMC Public Health. 2007;7:336.

22. Suominen K, Henriksson M, Suokas J, Isometsa E, Ostamo A, Lonnqvist J. Mental disorders and comorbidity in attempted suicide. Acta Psychiatr Scand. 1996;94(4):234-40.

23. Parkar SR, Dawani V, Weiss MG. Clinical diagnostic and sociocultural dimensions of deliberate selfharm in Mumbai, India. Suicide Life-Threatening Behav. 2006;36(2):223-38.

24. Jain V, Singh H, Gupta SC, Kumar S. A study of hopelessness, suicidal intent and depession in cases of attempted suicide. Indian Journal of Psychiatry. 1999;41(2):122-30. 
25. Bhatia SC, Khan MH, Mediratta RP, Sharma A. High risk suicide factors across cultures. The International Journal of Social Psychiatry. 1987;33(3):226-36.

26. Knipe D, Williams AJ, Hannam-Swain S, Upton S, Brown K, Bandara P, et al. Psychiatric morbidity and suicidal behaviour in low- and middle-income countries: A systematic review and meta-analysis. PLoS Medicine. 2019;16(10):e1002905.

27. Knipe D, Metcalfe C, Hawton K, Pearson M, Dawson A, Jayamanne S, Konradsen F, Eddleston M, Gunnell D. Risk of suicide and repeat self-harm after hospital attendance for non-fatal self-harm in Sri Lanka: a cohort study. The Lancet Psychiatry. 2019;6(8):659-66.

28. Eddleston M, Sheriff MHR, Hawton K. Deliberate self harm in Sri Lanka: an overlooked tragedy in the developing world. BMJ. 1998;317:133-42.

29. Ratnayeke L: Suicide in Sri Lanka. In: Suicide Prevention. Edited by Kosky ea. New York: Plenum Press; 1998: 139.

30. Burns JM, Patton GC. Preventive interventions for youth suicide: a risk factor-based approach. The Australasian New Zealand Journal of Psychiatry. 2000;34(3):388-407.

31. Gould MS, Greenberg T, Velting DM, Shaffer D. Youth suicide risk and preventive interventions: a review of the past 10 years. J Am Acad Child Adolesc Psychiatry. 2003;42(4):386-405.

32. Mann JJ, Apter A, Bertolote J, Beautrais AL, Currier D, Haas A, Hegerl U, Lonnqvist J, Malone KM, Marusic A, et al. Suicide Prevention Strategies: A Systematic Review. JAMA: the journal of the American Medical Association. 2005;294(16):2064-74.

33. LaFromboise T, Howard-Pitney B. The Zuni Life Skills Development Curriculum: Description and Evaluation of a Suicide Prevention Program. Journal of Counseling Psychology. 1995;42(4):479-86.

34. Gvion Y, Apter A. Suicide and Suicidal Behavior. Public Health Reviews 2012, 43(2):epub ahead of print..

35. Conner KR, Duberstein PR, Conwell Y, Seidlitz L, Caine ED. Psychological vulnerability to completed suicide: a review of empirical studies. Suicide Life-Threatening Behav. 2001;31(4):367-85.

36. Hettiarachchi J, Kodituwakku GC. Self poisoning in Sri Lanka: motivational aspects. The International Journal of Social Psychiatry. 1989;35(2):204-8.

37. Rajapakse T, Griffiths KM, Christensen H, Cotton S. A comparison of non-fatal self-poisoning among males and females, in Sri Lanka. BMC Psychiatry. 2014;14(1):221.

38. Jayasinghe NR, Foster JH. Deliberate self-harm/poisoning, suicide trends. The link to increased alcohol consumption in Sri Lanka. Archives of Suicide Research. 2011;15(3):223-37.

39. Jayasinghe NR, Foster JH. Acute poisoning and suicide/deliberate self-harm trends in Sri Lanka: Alcohol a cause for concern-Some further Observations. Asian journal of psychiatry. 2010;3(4):2334.

40. Obot IS, Room R, editors. Alcohol, Gender and Drinking Problems: perspectives from low and middle income countries. Geneva: Department of Mental Health and Substance Abuse, World Health Organization; 2005. 
41. Konradsen F, Hoek Wvd, Peiris P. Reaching for the bottle of pesticide-A cry for help. Self-inflicted poisonings in Sri Lanka. Soc Sci Med. 2006;62(7):1710-9.

42. Eddleston M, Ariaratnam CA, Meyer WP, Perera G, Kularatne AM, Attapattu4 S, Sheriff MHR, Warrell DA. Epidemic of self-poisoning with seeds of the yellow oleander tree (Thevetia peruviana) in northern Sri Lanka. Tropical Medicine International Health. 1999;4(4):266-73.

43. Nayak MB, Patel V, Bond JC, Greenfield TK. Partner alcohol use, violence and women's mental health: population-based survey in India. Br J Psychiatry. 2010;196(3):192-9.

44. Hawton K, Fagg J, McKeown SP. Alcoholism, alcohol and attempted suicide. Alcohol Alcohol. 1989;24(1):3-9.

45. Lamis DA, Malone PS, Jahn DR. Alcohol Use and Suicide Proneness in College Students: A Proposed Model. Mental Health Substance Use: Dual Diagnosis. 2014;7(1):59-72.

46. King RA, Schwab-Stone M, Flisher AJ, Greenwald S, Kramer RA, Goodman SH, Lahey BB, Shaffer D, Gould MS. Psychosocial and risk behavior correlates of youth suicide attempts and suicidal ideation. Journal of American Academy of Child Adolescents Psychiatry. 2001;40(7):837-46.

47. Samaraweera S, Sumathipala A, Siribaddana S, Sivayogan S, Bhugra D. Completed suicide among Sinhalese in Sri Lanka: a psychological autopsy study. Suicide Life-Threatening Behav. 2008;38(2):221-8.

48. Bridge JA, Goldstein TR, Brent DA. Adolescent suicide and suicidal behavior. J Child Psychol Psychiatry. 2006;47(3-4):372-94.

49. Sri Lanka Police. Crime Trends (Year 2005 to 2017) https://www.police.lk/index.php/crime-trends.

50. Black DW, Blum N, Pfohl B, Hale N. Suicidal behavior in borderline personality disorder: prevalence, risk factors, prediction, and prevention. J Pers Disord. 2004;18(3):226-39.

51. Tomko RL, Trull TJ, Wood PK, Sher KJ. Characteristics of borderline personality disorder in a community sample: comorbidity, treatment utilization, and general functioning. J Pers Disord. 2014;28(5):734-50.

52. Turecki G. Dissecting the suicide phenotype: the role of impulsive-aggressive behaviours. Journal of Psychiatry Neuroscience. 2005;30(6):398-408.

53. Senadheera C: Deliberate self-harm of children and adolescents: a hospital based study. In: Suicide in Sri Lanka: Past, Present and Future Transformations: 2013; University of Colombo: Department of Sociology, University of Colombo; 2013.

54. Hawton K, Catalan J. Attempted suicide: A practical guide to its nature and management. New York: Oxford University Press; 1987.

55. Kienhorst IC, De Wilde EJ, Diekstra RF, Wolters WH. Adolescents' image of their suicide attempt. J Am Acad Child Adolesc Psychiatry. 1995;34(5):623-8.

56. Jegannathan B, Kullgren G. Gender differences in suicidal expressions and their determinants among young people in Cambodia, a post-conflict country. BMC Psychiatry. 2011;11:47. 
Figures

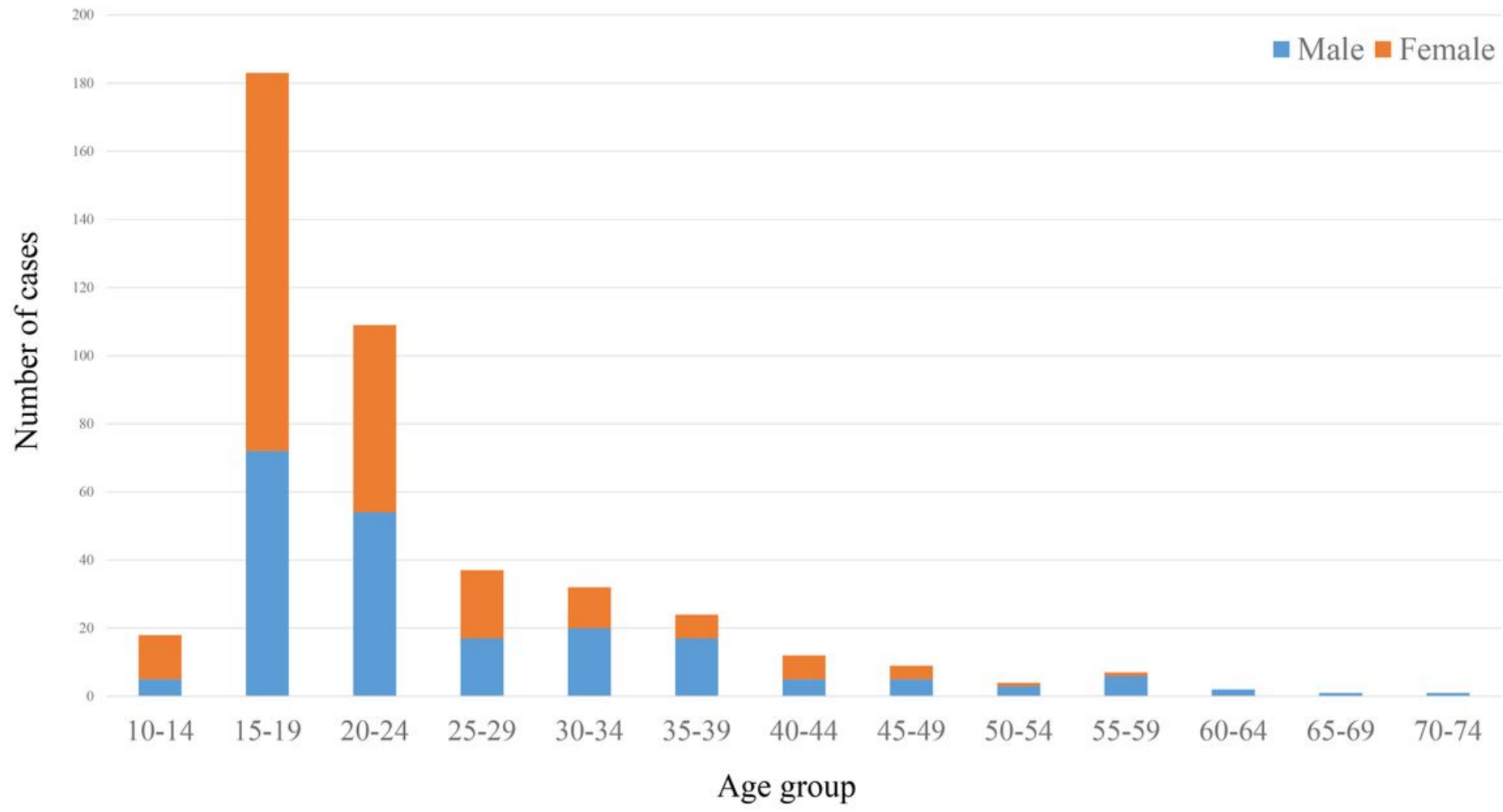

\section{Figure 1}

Number of cases by sex and age The sample consisted of $47.3 \%$ males and $52.7 \%$ females. $37 \%$ of males and $53.7 \%$ of females were aged below 20 years. About one third of the sample was in 20-29 year age group (male: $34.1 \%$ and female: $32.5 \%$ ). 